\title{
Stress and syllable structure durations in Greek
}

Antonis Botinis, Anastasia Iliadi, Michael Liontos, Elina Nirgianaki

Laboratory of Phonetics \& Computational Linguistics, University of Athens, Greece

https://doi.org/10.36505/ExLing-2012/05/0007/000213

\begin{abstract}
This is an experimental study of segmental durations as a function of lexical stress production and syllable structure in Greek. In accordance with a production experiment, the results indicate that lexical stress production has different effects on different syllable structure constituents. Thus, the vowels are lengthened more than prevocalic consonants whereas stress production has a shortening effect on postvocalic consonants. These results imply that vowels are the main carriers of stress distinctions in Greek with reference to duration correlates of stress production.
\end{abstract}

Key words: Greek, stress production, syllable structure, segment durations, prosody

\section{Introduction}

This is an experimental investigation of segmental durations as a function of lexical stress production and syllable structure in Greek. Lexical stress has a distinctive function in Greek and may be distributed in one of the three last syllables of the word. Syllable structure, on the other hand, has no weight distinction, i.e. light vs. heavy, and no effect on lexical stress application.

Greek has a dominant open syllable structure and intervocalic consonants are thus as a rule syllabified with the vowel on the right unless the consonant phonotactics are violated. The prevocalic consonants are referred to as "onset", the vowels as "nucleus" and the postvocalic consonants as "coda". The syllable is assumed to have a hierarchical structure, according to which the nucleus and coda constitute one syllable element, the "rhyme", which is branching with the onset, i.e. [[O]nset [[R]hyme [C]oda]]. Given that intervocalic consonants quite often violate the onset phonotactics of the syllable on the right, a consonant is consequently syllabified on the left, constituting the coda element of the syllable on the left.

The production of lexical stress is correlated with a variety of acoustic parameters. Among them, syllable lengthening is a constant acoustic correlate across different prosodic contexts and this lengthening is considerably bigger with respect to vowels than consonants (Botinis 1989, Fourakis et al. 1999). However, the duration variability of the coda consonant as a function of lexical stress production has not drawn attention in prosodic research, which is virtually an under-examined area.

In the present investigation, the main question is addressed to the duration correlates of coda consonants as a function of lexical stress production in Greek. Additional questions are addressed to the duration correlates of onset consonants and nucleus vowels and the results of this investigation are compared with results of other investigations.

ExLing 2012: Proceedings of 5th Tutorial and Research Workshop on Experimental Linguistics, 27-29 August 2012, Athens, Greece 


\section{Experimental methodology}

One production experiment was carried out in order to investigate segmental durations in different lexical stress and syllable structure contexts. The speech material consisted of 5 key words in the carrier sentence ['ipa ka'la] ("I said good"). All key words had the same CVCCV segmental structure, according to which the two intervocalic consonants have different syllable hosts. 10 female and 10 male speakers with standard Athenian pronunciation and no known speech disorders, at their twenties, produced the speech material 2 times at a normal tempo. The speech material was recorded in Athens University Phonetics Studio and analysed with the Praat sofware program. Segmental duration measurements were taken with standard criteria, in accordance with visual inspection of the soundwave and spectogram. The results were subjected to statistical analysis and processing with the SPSS software program.

\section{Results}

The results are reported with respect to the duration of word penultima syllable and its constituents (i.e. onset, nucleus, coda). Since the examined words were consisted of different segments (/'valti 'murla 'pen $\theta i \sim$ 'pafsi-naf'si/) and because absolute durations may have varied as a factor of speaking rate, syllable and segment "normalized" durations were examined, defined as the ratios of syllable duration over word duration and segment duration over syllable duration, respectively. Table 1 presents the mean duration (in ms) of each segment, syllable and word for each CV structure. The segment/syllable and syllable/word ratios are also presented.

In terms of syllable normalized duration, stressed syllables were significantly longer (0.684) than unstressed ones (0.548) [t(46) $=46.000$, $\mathrm{p}<.0001$ ] (Figure 1). A three-way Anova (gender x stress x position) with segment normalized duration as the dependent variable revealed a main effect of segment position in syllable $[F(2,36)=15.679, p<$ $0.0001]$. Post hoc tests indicated that there was a significant difference between onset and coda as well as nucleus and coda, but not between onset and nucleus position (onset: 0.360 , nucleus: 0.346 , coda: 0.293 ). A significant interaction between position and stress $[\mathrm{F}(2,36)=25.751$, $\mathrm{p}<0.0001]$ revealed that although segments at onset and mostly nucleus position were longer in stressed syllables, segments at coda position were longer in non-stressed syllables (Figure 2). Table 2 presents the mean normalized segment duration at onset, nucleus and coda position in stressed and non-stressed syllable condition. 
Table 1. Mean duration (in ms) of each segment, syllable and word for each $\mathrm{CV}$ structure and the ratios of segment duration over syllable duration and syllable duration over word duration.

\begin{tabular}{|c|c|c|c|c|c|}
\hline $\begin{array}{c}\text { CV } \\
\text { structure }\end{array}$ & Segment & Syllable & Word & $\begin{array}{c}\text { Segment / } \\
\text { Syllable }\end{array}$ & $\begin{array}{c}\text { Syllable / } \\
\text { Word }\end{array}$ \\
\hline$/$ CVltV/ & 90 & 270 & 400 & 0.225 & 0.675 \\
\hline$/ \mathrm{CVrlV/}$ & 82 & 246 & 415 & 0.197 & 0.592 \\
\hline$/ \mathrm{CVn} \theta \mathrm{V} /$ & 81 & 243 & 413 & 0.195 & 0.586 \\
\hline$/ \mathrm{CVfsV/}$ & 83 & 250 & 409 & 0.205 & 0.610 \\
\hline \hline
\end{tabular}

Table 2. Mean normalized segment duration (segment/syllable) at onset, nucleus and coda position in stressed and non-stressed syllable condition.

\begin{tabular}{|c|c|c|c|c|c|c|}
\hline \hline \multirow{2}{*}{$\begin{array}{c}\text { Syllable } \\
\text { position }\end{array}$} & \multicolumn{2}{|c|}{ Male } & \multicolumn{2}{c|}{ Female } & \multicolumn{2}{c|}{ Mean } \\
\cline { 2 - 7 } Onset & {$[+$ stress] } & {$[$-stress] } & [+stress] & {$[$-stress] } & [+stress] & [-stress] \\
\hline Nucleus & 0.380 & 0.359 & 0.356 & 0.346 & 0.368 & 0.352 \\
\hline Coda & 0.379 & 0.318 & 0.396 & 0.293 & 0.387 & 0.306 \\
\hline \hline
\end{tabular}

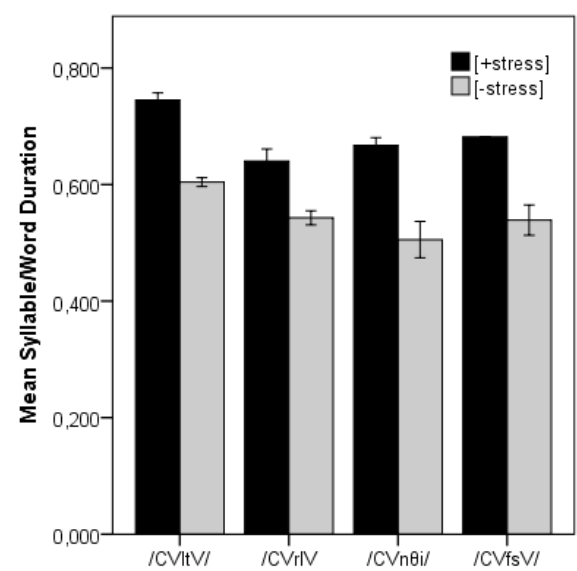

Figure 1. Mean normalized syllable/word durations as a function of stressed [+stress] and non-stressed [-stress] syllable condition.

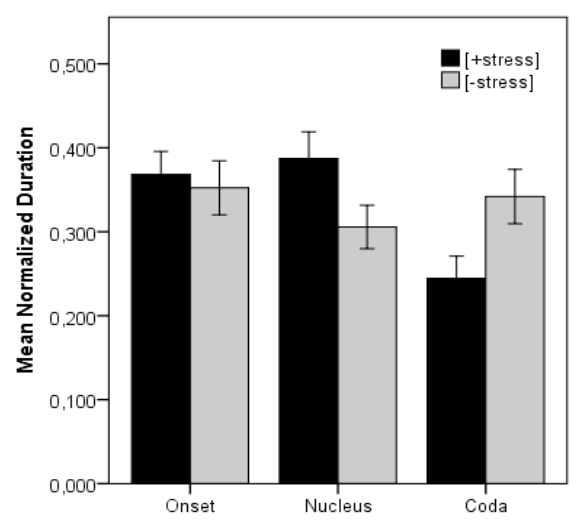

Figure 2. Mean normalized segment/syllable durations at onset, nucleus and coda position as a function of stressed [+stress] and non-stressed [-stress] syllable condition.

\section{Discussion}

The results of this investigation indicate that the production of lexical stress has different duration effects on different syllable structure constituents. Thus, the neucleus vowel is lengthened more than the onset consonant, whereas the coda consonants show the oposite effect. 
The above results are based on the hypothesis that coda consonants are permitted in the syllable structure of Greek. In accordance with the open syllable structure, which is predominant in Greek, intervocalic cluster consonants must syllabify on the right. However, when the phonotactis of the onset constituent of the syllable on the right are violated, a question is raised as to whether consonants may syllabify on the left.

A related to syllable structure study has provided experimental evidence that syllabification in Greek is mainly accomplished with reference to the non-violation of the phonotactics of the onset constituent of the syllable on the right (Chaida et al. 2012). This evidence is based on tonal structure and the production of voice fundamental frequency (F0), the rise of which is aligned with the beginning of the syllable, be it consonant or vowel. In accordance with the results of the above study (Chaida et al. 2012), the alignment of the F0 rise as a function of second syllable stress production was associated with either the first or second intervocalic consonant. In the former case, the phonotactics of the syllable on the right were not violated whereas, in the latter case, were violated. Hence, the first consonant was syllabified on the left, despite the dominant open syllable structure of Greek.

Assuming that a variety of different consonants may syllabify on the left and constitute thus the coda of the preceding syllable, a major issue is raised with reference to the temporal organization of syllable constituents as a function of lexical stress production. Segmental durations may vary in different prosodic contexts, including lexical stress and syllable structure ones (Botinis et al. 2001). In the present investigation, the shortening of the coda constituent in lexical stress context may be attributed to a complementary shortening in relation to the lengthening of the other onset and nucleus syllable constituents.

\section{Acknowledgements}

The research reported in the present study was supported by the project "Text Processing" at Athens University Department of Philology.

\section{References}

Botinis, A. 1989. Stress and Prosodic Structure in Greek. Lund: Lund University Press.

Botinis, A., Fourakis, M., Bannert, R. 2001. Prosodic interactions on segmental durations in Greek. Proceedings of th 7 th European Conference on Speech Communication and Technology, EUROSPEECH 2001, vol. 2, 923-926, Aalborg, Denmark.

Chaida, A., Gioulaki, K., Logotheti, A., Neocleous, N. 2012. Stress, tonal alignment and syllabification in Greek (this volume). 